\title{
Aplicabilidade de rhBMP-2 em diferentes técnicas de enxertia
}

\author{
rhBMP-2 applicability in different grafting techniques
}

\author{
Carlos Eduardo Zanella Pasquali \\ Liliane Cristina Onofre Casagrande* \\ Monique Estér Ponte ${ }^{* * *}$ \\ Thiago Aragon Zanella** \\ Fernanda Denti Brum ${ }^{* * * *}$ \\ Raphael Carlos Drumond Loro ${ }^{* * * *}$
}

\section{Resumo}

Objetivo: analisar a influência da rhBMP-2 em enxertos bucofaciais, apresentando pesquisas recentes, feitas em animais e em humanos, bem como as diferentes metodologias de aplicabilidade clínica e os resultados obtidos por seus autores. Revisão de literatura: para que seja possível a instalação de implantes ou a correção de defeitos ósseos há necessidade de que exista tecido ósseo de boa qualidade. Sem isso, as possibilidades de sucesso nos procedimentos de osteointegração e reabilitações bucofaciais, visando devolver ao paciente o volume ósseo perdido, são muito reduzidas. As proteínas morfogenéticas ósseas (BMPs) são substâncias osteoindutoras e têm sido utilizadas na regeneração óssea. A procura por materiais que apresentem características semelhantes às alcançadas com o enxerto autógeno, com o objetivo de reduzir a morbidade dos procedimentos de restauração das estruturas ósseas perdidas, fez com que as pesquisas avancem para o lado dos materiais sintéticos, como é o caso da rhBMP-2, principal proteína morfogenética indutora de tecido ósseo. Considerações finais: novos estudos são necessários para analisar a viabilidade e o sucesso da aplicação dessas proteínas. Para tanto, pode-se observar que essas proteínas têm uma excelente função na formação óssea.

Palavras-chave: Proteínas morfogenéticas ósseas. Regeneração óssea. Osseointegração. Proteínas da superfamília de TGF-beta.

\section{Introdução}

Técnicas de enxerto ósseo surgiram para suprir perdas de volume nos sentidos horizontais e verticais, em pacientes com quantidade óssea reduzida, visto que o sucesso de reabilitações bucofaciais depende não somente do treinamento e da experiência do profissional, mas também da quantidade e da densidade de osso disponível ${ }^{1,2}$.

O tecido ósseo tem as seguintes propriedades de reparação e formação: osteogênese que é a formação óssea mediada por osteoblastos; osteoindução, mediada por BMPs, induzindo a formação óssea ectópica por meio de células mesenquimais; e osteocondução, relacionado à composição e à estrutura (arcabouço). Tais propriedades têm papel importante nos diferentes mecanismos de formação óssea dos enxertos, os quais podem ter diferentes origens: autógenos, homógeno, xenógeno e aloplásticos ${ }^{3-6}$. Osso autógeno ainda é o "padrão ouro" para procedimentos de reconstrução", apesar da grande morbidade ${ }^{8}$.

Em estudos recentes, pesquisadores isolaram a principal proteína para regeneração óssea, a proteína morfogenética (BMP), e derivaram sinteticamente a Proteínas Morfogenéticas Ósseas Recombinantes Humanas (rhBMP-2). Essa proteína funciona como regulador de crescimento e diferenciação celular, induzindo a transformação de células-tronco em células produtoras de tecidos ósseos ou vasculares ${ }^{3,6}$. 
Fazendo com que as pesquisas avancem para o lado dos materiais sintéticos ${ }^{9}$, rhBMP-2 foi testado em diversos estudos, mostrando efeitos de indução óssea ${ }^{7,10,11}$. Esse é citado clinicamente como um relevante indutor ósseo, num largo espectro periodontal e crânio facial, nos modelos animais de grande porte $^{10-19}$.

Cuidados como limitações anatômicas ${ }^{20}$, propriedades de transporte ${ }^{21-23}$, características da molécula $\mathrm{BMP}^{23-25}$ e dose ${ }^{26-28}$ são necessários para otimizar os resultados do tratamento com o uso de BMPs.

Este trabalho terá como meta realizar uma ampla revisão de literatura a respeito de técnicas de enxerto bucofacial utilizando BMPs.

\section{Revisão de literatura}

Devido a diferentes graus de indução de osteogênese, para um prognóstico aceitável do enxerto utilizado, o material de enxertia é de fundamental importância ${ }^{29}$. Os enxertos podem ser divididos em autógenos, homógenos, xenógeno e aloplásticos ${ }^{3,4}$.

O padrão a ser alcançado pelos enxertos ósseos é o dos enxertos autógenos. Todavia, esses enxertos requerem duas fendas cirúrgicas: uma para área receptora e outra para a área doadora, gerando cirurgias mais traumáticas e de execução mais complexa do que as de enxerto homógeno ou aloplástico, em que o material a ser enxertado pode ser obtido comercialmente. Estudos comparativos são encontrados em literaturas e devem funcionar como uma base de conhecimento biológico para que o cirurgião-dentista opte pelo que melhor se adequar à sua situação clínica específica ${ }^{29-31}$.

Com o objetivo de reduzir a morbidade dos procedimentos de restauração das estruturas ósseas perdidas, a procura por materiais que apresentem características semelhantes às alcançadas com 0 enxerto autógeno fez com que as pesquisas avancem para o lado dos materiais sintéticos ${ }^{32}$.

As Proteínas Morfogenéticas Ósseas foram, primeiramente, descritas por Urist e Strates $^{33}$ (1971) e, mais tarde, Wozney et al. ${ }^{34}$ (1988) clonaram os genes das BMPs. Desde então, as rhBMPs têm sido estudadas na tentativa de neoformação óssea por apresentarem alta capacidade osteoindutora e entre essas destacamos o rhBMP- $2^{35}$.

$\mathrm{O}$ grande diferencial desse está principalmente na possibilidade de eliminar os procedimentos de coleta de osso autógeno em sítios intra e extraorais. Além disso, a probabilidade de aumento na deposição ósseo estimula a utilização desse material ${ }^{36,37}$.

As BMPs formam um grupo de glicoproteínas classificadas em oito grupos. Essas proteínas podem ter origem bovina e humana, pertencendo a uma grande família chamada de Fator de Crescimento Beta (TGF), uma vez que têm em suas fórmulas uma sequência muito similar de aminoácidos entre elas. As proteínas que foram isoladas (ou purificadas) até então são: BMP-1; BMP-2; BMP-3 (Osteogenina); BMP-4; BMP-5; BMP-6, BMP-7 e BMP-8; cada uma dessas proteínas tem uma capacidade osteoindutora diferente ${ }^{38}$. As BMPS recombinantes 2, 4 e 7 induzem formação óssea, sendo as mais testadas clinicamente ${ }^{39}$.

O rhBMP-2, por exemplo, tem a maior capacidade osteoindutora dentre todas as $\mathrm{BMPs}^{40}$, participando da diferenciação de células mesenquimais em células com fenótipo de osteoblastos, aumentando a atividade da fosfatase alcalina, do Camp (em resposta ao hormônio da paratireoide) e de osteocalcina $^{41,42}$

Testes com os mais variados tipos de carreadores tornam-se interessantes e necessários para obtermos o carreador ideal, devido às varias formas existentes de $\mathrm{BMPs}^{43}$. O carreador deve ser absorvível na medida em que for ocorrendo à formação óssea, além de seguro, biodegradável, biocompatível e formulado para permitir tamanhos e formas adequadas para o enxerto ${ }^{32}$. Apesar de a BMP induzir formação óssea quando implantada sozinha, associada com outros substratos ou meios, conseguimos resultados mais efetivos ${ }^{38}$.

O carreador deve promover uma lenta liberação da BMP e deve ter robustez suficiente para manter a integridade dos bordos, promovendo a manutenção espacial e mantendo estáveis os bordos do retalho (arcabouço) ${ }^{44}$. Quando se associa a BMP com um carreador, propicia-se imobilidade da proteína na área, diminui-se a quantidade de BMP necessária e o tempo para que ocorra a indução ${ }^{45}$.

Dentre os materiais testados em associação à BMP, ressaltamos: hidroxiapatita ${ }^{35,46}$; esponjas de colágeno reabsorvível ${ }^{16,21,25,35,46-48 ;}$ politetrafluoretileno expandido $^{49,50}$; osso bovino ${ }^{16,21,51-54}$ e osso autógeno ${ }^{55}$. Os carreadores mais utilizados são a hidroxiapatita e o colágeno, pois são compostos presentes na estrutura óssea, absorvendo naturalmente a BMP $\mathrm{BM}^{56}$

Efeitos adversos também vêm sendo relatados com o uso de rhBMP-2, tais como reações alérgicas locais, perda do enxerto, infecções, edema e complicações no reparo, apesar dos resultados clínicos favoráveis ${ }^{57,58}$

Foi investigado se há melhora na ósseointegração implante-osso por meio da utilização de rhBMP-2 em testes com coelhos, mensurando força de ligação por teste de tração. Os autores concluíram que rhBMP-2 melhora a qualidade e a quantidade de osseointegração osso-implante ${ }^{59}$.

Os efeitos na formação óssea, utilizando rhBMP-2 em defeitos alveolares, foi testado em mandíbulas de jovens primatas não humanos, obteve uma regeneração óssea satisfatória, após o implante cirúrgico de rhBMP-2, mostrando-se uma alternativa eficaz para substituição aos enxertos autógenos $^{60}$.

A eficácia de aumento do osso vertical foi avaliada no osso craniano de 15 coelhos, revelando que um bloco córtico-esponjoso de osso humano, agre- 
gado com rhBMP-2, poderia ser uma opção de tratamento alternativo para aumento ósseo vertical ${ }^{61}$.

Para examinar a eficácia de rhBMP-2 em distração osteogênica, os autores relataram a consolidação óssea em 21 coelhos, sugerindo que a rhBMP-2 promove a formação de osso em distração osteogênica ${ }^{62}$.

Ao se comparar o aumento do seio maxilar, um grupo com rhBMP-2 em uma esponja de gelatina (PLPG) e outro com osso pélvico esponjoso autólogo, durante a colocação de diferente sistemas de implantes dentários, foi realizado um estudo em nove ovelhas adultas, realizando avaliações de contato implante-osso (BIC) e densidade óssea (BD). O uso de rhBMP-2 com esponja de gelatina aumentou o BIC, bem como a BD nos seios maxilares aumentados se comparados ao osso autólogo ${ }^{9}$.

Foi realizado um relato clínico em 14 pacientes, os quais foram selecionados a partir de um grupo maior, recebendo rhBMP-2 com carreador de colágeno em diferentes categorias de defeitos mandibulares: doenças neoplásicas e osteomielite (relacionadas com bifosfonatos ou irradiação). Esse estudo indicou que o uso de rhBMP-2, sem uso concomitante de materiais de enxerto ósseo, em grandes defeitos mandibulares, produz uma excelente regeneração óssea da área receptora e estabelece a base para o retorno da função protética ${ }^{63}$.

Uma revisão sistemática foi realizada por meio de estudos clínicos/série de casos, publicada de 1980 até 2012, usando rhBMP-2/ACS (esponja carreadora de colágeno reabsorvível) quando utilizado para correção de defeitos alveolares/aumento do seio maxilar em humanos. Observou-se uma formação óssea clinicamente significativa no aumento do seio maxilar, permitindo a colocação de implantes dentários em diferentes concentrações de rhBMP-2 e em cavidades de extração. A rhBMP-2/ACS manteve altura do rebordo alveolar, reforçando simultaneamente a largura desse. Dessa forma, rhBMP-2/ ACS aparece como uma alternativa promissora ao enxerto ósseo autógeno ${ }^{64}$.

Um estudo clínico randomizado foi realizado comparando o efeito de rhBMP-2 em uma esponja carreadora de colágeno reabsorvível (ACS), com enxerto autógeno (região retromolar de mandíbula), para aumento de maxila atrófica anterior. Uma malha de titânio foi usada para proporcionar espaço e estabilidade da ferida. Em seis meses não foram observadas diferenças significativas no ganho ósseo horizontal entre rhBMP-2/ACS e enxerto ósseo autógeno. Foram colocados 62 implantes depois de seis meses de cura sem diferenças significativas entre os dois grupos para o número de implantes, o tamanho do implante, a estabilidade primária e sobrevivência ${ }^{65}$.

Marx et al. ${ }^{66}$ (2013) realizaram estudo clínico randomizado, em pacientes com defeitos verticais de maxila, utilizando duas formas de enxertos; um grupo de vinte pacientes com enxerto autógeno e outro grupo de vinte pacientes com enxerto compos- to de rhBMP-2, esponja de colágeno acelular (ACS), osso esponjoso alogênico liofilizado (CCFDAB) e plasma rico em plaquetas (PRP). Como resultado, o enxerto composto de rhBMP-2 / ACS-CCFDAB-PRP teve previsibilidade comparável ao enxerto autógeno, com custo igual, menor morbidade, formação óssea mais viável com menor quantidade de partículas residuais, porém com maior edema. Ressalta-se que enxerto composto é capaz de atingir resultados equivalentes a enxertos autógenos ${ }^{66}$.

Apesar de todas as vantagens quanto ao uso de rhBMP-2, essa é altamente sobre-expressa na maioria dos carcinomas de pulmões debilitados. Teste em ratos revela que BMP-2 aumenta a neovascularização e a resposta angiogênica de tumores de desenvolvimento, sugerindo, com os dados deste estudo, que a rhBMP-2 pode envolver a ativação de células endoteliais. No entanto, um mecanismo que revele seu papel no câncer ainda não foi estabelecido ${ }^{67}$.

\section{Discussão}

A difusão do uso dos implantes dentários e de enxertos ósseos, no meio odontológico, induziu os pesquisadores a buscarem substâncias que pudessem contribuir para a formação de um tecido ósseo de qualidade e em quantidade suficiente para a instalação dos implantes e para reabilitações bucofaciais, assim como para melhorar e/ou acelerar o processo de osseointegração, fundamentais para o sucesso dessa alternativa clínica.

A proteína morfogenética BMP-2 induz a transformação de células-tronco em células produtoras de tecidos ósseos ou vasculares, funcionando como reguladores de crescimento e de diferenciação celular. É um assunto recente para a área da Odontologia, entretanto, o avanço nas pesquisas sobre biomateriais tem apresentado uma melhora da resposta tecidual em regeneração óssea guiada, enxertos e implantes com resultados mais seguros, porém menos invasivos e semelhantes ao enxerto autólogo.

Alguns questionamentos têm sido abordados devido à identificação de BMPs em carcinomas de pulmões doentes, expressando altos níveis de BMP-2. Poderiam essas atuar como agentes oncogênicos ou estimular a oncogênese? $\mathrm{O}$ uso de BMPs, porém, não demonstrou elicitar respostas oncológicas. Os eventos oncológicos provavelmente aumentaram a expressão de BMPs, ativas não somente na diferenciação celular, mas também na angiogênese. A vida curta das BMPs também contribui para que a indução de neoplasias pelo uso de BMPs mostre-se improvável ${ }^{67}$.

Um grande número de estudos envolvendo BMPs está disponível, porém esses devem ser analisados com cautela, já que a maioria envolve pequenos grupos de amostras de população e não abrange grupo-controle, além do fato de a maioria dos trabalhos terem sido realizados em animais e em defeitos 
criados cirurgicamente nesses espécimes. Apesar desses animais permaneceram sob padronização e controle de alimentação e de higiene, dificilmente se consegue essas situações em estudos que envolvem a análise de seres humanos. Por esse motivo, os resultados obtidos entre esses estudos podem diferir substancialmente, possibilitando a ocorrência de vieses tendenciosos quanto à sua avaliação.

Ressaltamos que todos os artigos estudados sugeriram novas pesquisas para confirmar os resultados até hoje encontrados, havendo, ainda, a necessidade de muitos estudos pré-clínicos e clínicos para analisar a viabilidade e o sucesso da aplicação dessas proteínas no caso de implantes e enxertos bucofaciais em humanos.

\section{Considerações finais}

Ao considerarmos a presente revisão, é pertinente concluir que a aplicação deas substâncias mencionadas nos defeitos ósseos promove o preenchimento da região, com uma neoformação óssea de densidade e trabeculado similares ao osso normal, além de um aumento da cortical e da altura alveolar vertical, podendo ser uma alternativa real aos enxertos ósseos autógenos.

\section{Abstract}

Objective: to examine the influence of rhBMP-2 in bucco-facial grafts, presenting recent research on animals and humans, as well as different approaches to clinical application and the results obtained by the authors. $\mathrm{Li}$ terature Review: to allow either the installation of implants or the correction of bone defects, high quality bone tissue is required. Otherwise, the chances of success in osseointegration procedures and bucco-facial rehabilitation that aim to provide the patient with the bone volume lost are greatly reduced. Bone morphogenetic proteins (BMPS) are osteoinductive substances and have been used in bone regeneration. The search for materials presenting characteristics similar to those achieved with autograft, aiming to reduce morbidity in procedures of restoration of lost bone structures, allowed research to develop toward synthetic materials, such as the rhBMP-2, which is the main morphogenetic protein inducer of bone tissue. Final Considerations: further studies are needed to analyze the feasibility and success of the application of these proteins. Hence, it may be observed that these proteins play an important role in bone formation.

Keywords: Bone Morphogenetic Proteins. Bone Regeneration. Osseointegration. TGF-beta Superfamily Proteins.

\section{Referências}

1. Bastos Neto FVR. Implantologia Ciência e Prática. Maringá: Dental Press Editora 2011:1; 305-37.

2. Dahlin C, Linde A, Gottlow J, Nyman S. Healing of bone defects by guided tissue regeneration. Plast Reconstr Surg 1988; 81(5):672-6.

3. Wikesjo UME, Qahash M, Polimeni G, Susin C, Shanaman $\mathrm{RH}$, Rohrer MD, et al. Alveolar ridge augmentation using implants coated with recombinant human bone morphogenetic protein-2: histologic observations. J Clin Periodontol 2008; 35:1001-10.

4. Scarano A, Carinci F, Assenza B, Piattelli M, Murmura G, Piattelli A. Vertical ridge augmentation of atrophic posterior mandible using an inlay technique with a xenograft without miniscrews and miniplates: case series. Clin Oral Implants Res. 2011; 22(10):1125-30.

5. Urist M. Bone morphogenetic protein induced bone formation in experimental animals and patients with large bone defects. CIBA Foundation Symposium Cell and molecular biology of vertebrate hard tissues 1988; London. London: John Wiley \& Sons; 1988.

6. Spagnoli DB, Marx RE. Dental Implants and the Use of rhBMP-2. Dent Clin North Am 2011; 55(4):883-907.

7. Raghoebar GM, Brouwer TJ, Reintsema H, Van Oort RP. Augmentation of the maxillary sinus floor with autogenous bone for the placement of endosseous implants: a preliminary report. J. Oral Maxillofac Surg 1993; 51(11):1198-1203.

8. Silva FM, Cortez AL, Moreira RW, Mazzonetto R. Complications of intraoral donor site for bone grafting prior to implant placement. Implant Dent 2006; 15(4):420-6.

9. Gutwald R, Haberstroh J, Stricker A, Ruuther E, Otto F, Xavier SP et al. Influence of rhBMP-2 on bone formation and osseointegration in different implant systems after sinus-floor elevation. An in vivo study on sheep J. Craniomaxilojac Surg 2010; 38:571-

10. Boyne PJ, Shabahang S. An evaluation of bone induction delivery materials in conjunction with root-form implant placement. Int J Periodontics Restorative Dent 2001; 21(4):333-43.

11. Schwartz Z, Simon BJ, Duran MA, Barabino G, Chaudhri R, Boyan BD. Pulsed electromagnetic fields enhance BMP-2 dependent osteoblastic differentiation of human mesenchymal stem cells. J. Orthop. Res. 2008; 26(9):1250-55.

12. Toriumi DM, Kotler HS, Luxenberg DP, Holtrop ME, Wang EA. Mandibular reconstruction with a recombinant bone-inducing factor. Functional, histologic, and biomechanical evaluation. Arch Otolaryngol Head Neck Surg 1991; 117:1101-12.

13. Toriumi DM, O'Grady K, Horlbeck DM, Desai D, Turek TJ, Wozney J. Mandibular reconstruction using bone morphogenetic protein 2: long-term follow-up in a canine model. Laryngoscope 1999; 109:1481-9.

14. Ishikawa I, Kinoshita A, Oda S, Roongruangphol T. Regenerative therapy in periodontal diseases. Histological observations after implantation of rhBMP-2 in the surgically created periodontal defects in adults dogs. Dentistry in Japan 1994; 31:141-6.

15. Sigurdsson TJ, Lee MB, Kubota K, Turek TJ, Wozney JM, Wikesjoo UME. Periodontal repair in dogs: recombinant human bone morphogenetic protein-2 significantly enhances periodontal regeneration. J Periodontol 1995; 66:131-8.

16. Sigurdsson TJ, Nygaard L, Tatakis DN, Fu E, Turek TJ, Jin $\mathrm{L}$ et al. Periodontal repair in dogs: evaluation of rhBMP-2 carriers. Int J Periodontics Restorativ Dent 1996; 16:525-37. 
17. Sigurdsson TJ, Fu E, Tatakis DN, Rohrer MD, Wikesjoo UME. Bone morphogenetic protein-2 enhances peri-implant bone regeneration and osseointegration. Clin Oral Implants Res 1997; 8:367-74.

18. Sigurdsson TJ, Nguyen S, Wikesjoo UME. Alveolar ridge augmentation with rhBMP-2 and bone to implant contact in induced bone. Int J Periodontics Restorative Dent 2001; 21:461-73.

19. Mayer M, Hollinger J, Ron E, Wozney J. Maxillary alveolar cleft repair in dogs using recombinant human bone morphogenetic protein-2 and a polymer carrier. Plas and Reconst Surg 1996; 98:247-59.

20. Barboza EP, Duarte ME, Geolas L, Sorensen RG, Riedel GE, Wikesjoo UME. Ridge augmentation following implantation of recombinant human bone morphogenetic protein-2 in the dog. J Periodontol 2000; 71:488-96.

21. Sigurdsson TJ, Nygaard L, Tatakis DN,Fu E,Turek TJ,Jin L,etal. Periodontal repair in dogs: evaluation of rhBMP-2 carriers. Int J Periodontics Restorative Dent 1996; 16: 524-37.

22. Uludag H, D'Augusta D, Palmer R, Timony G, Wozney J. Characterization of rhBMP-2 pharmacokinetics implanted with biomaterial carriers in the rat ectopic model. J Biomed Mater Res 1999; 46:193-202.

23. Winn SR, Hasan U, Hollinger JO. Carrier systems for bone morphogenetic proteins. Clin Orthop Relat Res 1999; 95-106.

24. Uludag H, Golden J, Palmer R, Wozney JM. Biotinated bone morphogenetic protein-2: in vivo and in vitro activity. Biotechnol Bioeng 1999; 65:668-72.

25. Friess W, Uludag H, Foskett S, Biron R, Sargeant C. Characterization of absorbable collagen sponges as rhBMP-2 carriers. Int J Pharm 1999; 187:91-9.

26. Kanatani M, Sugimoto T, Kaji H Kobayashi T,Nishiyama $\mathrm{K}$, Fukase $\mathrm{M}$ et al. Stimulatory efect of bone morphogenetic protein-2 on osteoclast-like cell formation and bone-resorbing activity. J Bone Miner Res 1995; 10:1681-90.

27. Sandhu HS, Kanim LE, Kabo JM, Toth JM, Zeegem EN, Liu $\mathrm{D}$, et al. Effective doses of recombinant human bone morphogenetic protein-2 in experimental spinal fusion. Spine 1996; 21(18):2115-22.

28. Wurzler KK, DeWeese TL, Sebald W, Reddi AH. Radiation-induced impairment of bone healing can be overcome by recombinant human bone morphogenetic protein-2. J Craniofac Surg 1998; 9:131-7.

29. Sendyk WR, Sendyk CL. Reconstrução óssea por meio do levantamento do assoalho do seio maxilar. São Paulo: Santos; 2002. p. 109-22.

30. Hirsch JM, Ericsson I. Maxillary sinus augmentation using mandibular bone grafts and simultaneous installation of implants. A surgical technique. Clin Oral Implantal Res 1991; 2(2):91-6.

31. Misch CE, Dietsh F. Endosteal implants and iliac crest grafts to restore severely resorbed totally edentulous maxilla: A retrospective study. J Oral implantol 1993; 20(2):100-10.

32. Fardin AC, Jardim ECG, Pereira FC, Guskuma MH, Aranega AM, Garcia Júnior IR. Innov Implant J. Biomater Esthet 2010; 5(3):48-52.

33. Urist MR; Strates BS. Bone Morphogenetic Protein. J Dent Res 1971; 50(6): 1392-406.

34. Wozney JM. Novel Regulators of Bone Formation: Molecular Clones and Activities, Science 1988; 242(4885):1528-34.

35. Barboza EP. Ridge Augmentation Following Implantation of Recombinant Human Bone Morphogenetic Protein-2 in the Dog. J Periodontal Chicago 2000; 71(3):488-96.
36. Herford AS, Boyne PJ, Williams RP. Clinical applications of rhBMP-2 in maxillofacial surgery. J Calif Dent Assoc 2007; 35:335-41.

37. Hart KL, Bowles D. Reconstruction of alveolar deffects using titanium-reinforced porous polyethylene as a containment device for recombinant human bone morphogenetic protein 2. J Oral Maxillofac Surg 2012; 70:811-20.

38. Ripamonti U, Reddi AH. Periodontal Regeneration: Potential Role of Bone Morphogenetic Protein. Journal Periodontol Restorative 1994; 29(4):225-35.

39. Tuominen T,Tainsa T,Tew kkanen J,Niemineu P,Lindhaen TC, Jalovaara P. Native Bovine Bone Morphogenetic Protein Improves the Potential of Biocoral to Heal Segmental Canine Ulnar Defects. Int Orthop, 2000; 24(5): 289-94.

40. Wozney JM. The Bone Morphogenetic Protein Family and Osteogenesis. Mol Reprod Dev. 1992; 32(2),160-7.

41. Thies RS, Bauduy M, Ashton BA, Kurtzberg L, Wozney JM, Rosen V. Recombinant human bone morphogenetic protein-2 induces osteoblastic differentiation in W-20-17 stromal cells. Endocrinology 1992; 130:1318-24.

42. Yamaguchi A, Katagiri T, Keda T, Wozney JM, Rosen V, Wang EA et al. Recombinant human bone morphogenetic protein-2 stimulates osteoblastic maturation and inhibits myogenic differentation in vitro. J Cell Biol 1991; 113:(3):681-7.

43. Gonçalves EAL, Guimarães SAC, Garcia RB. Proteínas morfogenéticas ósseas: terapêutica molecular no processo de reparotecidual. Rev Odontol Univ Sao Paulo 1998; 12(3): 299304.

44. King GN. The Importance of Drug Delivery to Optimize the Effects of Bone Morphogenetic Proteins During Periodontal Regeneration. Curr Pharm Biotechnol 2001; 2(2):131-42.

45. Cirano FR. Propriedades e Mecanismo de Ação das Proteínas Morfogenéticas Ósseas (BMPs). Sobrape 2005; 5(2):33-9.

46. Guimarães MCM. Pool of Bovine Morphogenetic Proteins and Guides Tissue Regeneration in the Treatment of Intrabody Periodontal Defect: Clincal Measurements. J App Oral Sci 2004; 12(1):70-7.

47. Giannobile WV. Gene Therapy of Morphogenetic Protein for Periodontal Tissue Enginnering. J Periodontol 2003; 74(2):202-13.

48. Selvig KUM. Bone Repair Following Recombinant Human Bone Morphogenetic Protein-2 Stimulated Periodontal Regeneration. J Periodontol 2002; 73(9):1020-9.

49. Wikesjo ULFME. Periodontal repair in dogs: rhBMP-2 significantly enhances bone formation under provisions for guided tissue regeneration. J of Cli Periodontol 2003; 30(8):705-14.

50. Wikesjo ULFME. Periodontal repair in dogs: space-providing ePTFE devices increase rhBMP-2/ACS-induced bone formation. J Clin Periodontol 2003; 30(8):715-25.

51. Ferretti CRU. Human Segmental Mandibular Defects Treated With Naturally Derived Bone Morphogenetic Proteins. J Craniofac Surg 2002; 13(3):434-44.

52. Jung RE. Effect of rhBMP-2 on guided bone regeneration in humans. Clin. Oral Implants Res 2003; 14(5):556-68.

53. Barboza EP. Effect of Recombinant Human Bone Morphogenetic Protein-2 in an Absorbable Collagen Sponge With Space-Providing Biomaterials on the Augmentation of Chronic Alveolar Ridge Defects. J Periodontol 2004; 75(5):702-8.

54. Munhoz ETA. Avaliação Radiográfica de Enxerto Ósseo Xenogênico em Alvéolos de Terceiros Molares Inferiores Não irrompidos [Dissertação de Mestrado]. Bauru: Faculdade de Odontologia de Bauru. Universidade de Sao Paulo; 2005. 
55. Ueda JK. Estudo comparativo da substituição óssea frente a enxerto de osso autógeno e proteína morfogenética óssea ao lado de implantes de titânio. Rev Dental Press Periodontia Implantol 2007; 1(1):76-84.

56. Viana RI. Estudo in Vitro da Citocompatibilidade do Pool de BMP Conjugado à Hidroxiapatita Utilizado como Ósseoindutor [Dissertação de Mestrado]. Campinas: Unicamp. Faculdade de Biologia, Universidade Estadual de Campinas, Campinas-SP; 2003.

57. Boyne PJ, Marx RE, Nevins M, Triplett G, Lazaro E, Lilly LC, et al. A feasibility study evaluating rhBMP-2/absorbable collagen sponge for maxillary sinus floor augmentation. Int J Periodontics Restorative Dent 1997; 17:11-25.

58. Woo EJ. Adverse events reported after the use of recombinant human bone morphogenetic protein 2. J Oral Maxillofac Surg 2012; 70:765-7.

59. Lan J, Wang ZF, Shi B, Xia HB, Cheng XR. The influence of recombinant human BMP-2 on bone-implant osseointegration: biomechanical testing and histomorphometric analysis. Int J Oral Maxillofac Surg 2007; 36: 345-9.

60. Marukawa E, Asahina I,Oda M, Seto I, Alam I, Enomoto S. Bone regeneration using recombinant human bone morphogenetic protein-2 (rhBMP-2) in alveolar defects of primate mandibles Br J Oral Maxillofac Surg 2001; 39:452-9.

61 Kim SJ, Shin HS, Shin SW. Effect of bone block graft with rhBMP-2 on vertical bone augmentation. Int J Oral Maxillofac. Surg 2010; 39: 883-8.

62. Yonezawa H, Harada K, Ikebe, Shinohara M, Enomoto S. Effect of recombinant human bone morphogenetic protein-2 (rhBMP-2) on bone consolidation on distraction osteogenesis: a preliminary study in rabbit mandibles $\mathrm{J}$ Craniomaxillofac Surg 2006; 34:270-6.

63. Alan S. Herford, and Philip J. Boyne Reconstruction of Mandibular Continuity Defects With Bone Morphogenetic Protein-2 (rhBMP-2). American Association of Oral and Maxillofacial Surgeons J Oral Maxillofac Surg 2008; 66:616-624.

64. Freitas RM, Spin-Neto R, Junior EM, Pereira LA, Wikesjö UM, Susin C. Alveolar Ridge and Maxillary Sinus Augmentation Using rhBMP-2: A Systematic Review. Clin Implant Dent Relat Res. 2013

65. Freitas RM, Susin C, Spin-Neto R, Marcantonio C, Wikesjö UM, Pereira LA, Marcantonio E Jr. Horizontal ridge augmentation of the atrophic anterior maxilla using rhBMP-2/ ACS or autogenous bone grafts: a proof-of-concept randomized clinical trial. J Clin Periodontol 2013; 40(10):968-75.

66. Marx RE, Armentano L, Olavarria A, Samaniego J. rhBMP-2/ ACS grafts versus autogenous cancellous marrow grafts in large vertical defects of the maxilla: an unsponsored randomized open-label clinical trial. Int J Oral Maxillofac Implants 2013; 28(5):243-51.

67. Langenfeld EM, Langenfeld J. Bone Morphogenetic Protein-2 Stimulates Angiogenesis in Developing Tumors Mol Cancer Res 2004; 2:141-9.

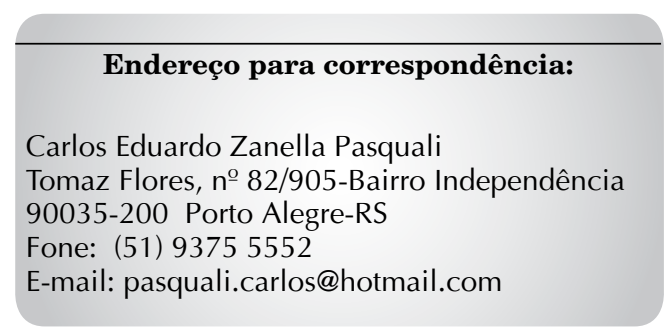

Recebido: 20/05/2014. Aceito: 21/07/2014. 